METALLURGY AND FOUNDRY ENGINEERING - Vol. 36, 2010, No. 2

Marek Wojtaszek*, Piotr Dudek**

\title{
INFLUENCE OF CLOSED-DIE HOT COMPACTION PARAMETERS ON SELECTED PROPERTIES OF PM AL-SI-FE-CU MATERIALS
}

\section{INTRODUCTION}

The forming processes based on powder metallurgy make it possible to obtain materials showing properties which are difficult to achieve by casting. Powders or powder mixtures used as initial material allow to easily modify the chemical composition. The possibility to obtain microstructure of small grain size is also an advantage, especially in case of materials produced from pulverized powders, which is an effect of short particle solidification time [1]. In case of materials destined for constructional elements it is necessary to obtain suitably high relative density, which depends on material grade, working conditions of an element and loading scheme. In case of some powders it is possible to achieve high relative density of PM products by means of applying compaction and sintering processes. Powders produced from low-ductile, hard or fine-grained materials can be processed with application of plastic working or closed-die hot compaction [2]. During forming of products by means of plastic working and compaction, the material flow occurs. As a result of hot compaction, the decrease of initial material's volume and increase of its density is observed, along with the consolidation of powder particles. The parameters determining the properties of obtained products include: temperature, punch unit pressure and pressure duration [3]. Closed-die hot compaction can be applied instead of compaction and sintering, when the chemical composition or powder morphology makes it impossible to obtain the stable compact at room temperature, regardless of pressure level. As an example of hard-cold-deformable materials, Al-based alloys can be given, with silicon as basic alloying component. These alloys show some interesting properties, such as low specific gravity, high strength, good thermal conduction and wear resistance. They can be modified as needed, by introducing reinforcing phase or additional alloying components $[4,5,6]$. Their applications include constructional elements working in elevated or variable temperatures, mainly in automotive industry.

* Ph.D., ** M.Sc: Faculty of Metals Engineering and Industrial Computer Science, AGH University of Science and Technology, Krakow, Poland; e-mail: mwojtasz@metal.agh.edu.pl 


\section{EXPERIMENT}

Objective and scope of research. The research aimed at the determination of the influence of forming parameters on selected properties of products obtained in closed-die hot compaction of Al-Si-Fe-Cu type alloy powder. The scope of research included the preparation of samples in closed-die hot compaction process, with the parameters set for the experiment, determination of selected properties of obtained products and the analysis of microstructure.

Material. The initial material used in the experiment was pulverized Al17Si5Fe3Cu1.1Mg0.6Zr alloy powder, with particles of spherical shape and size smaller than $40 \mu \mathrm{m}$.

Preparation of samples. The parameters of heating and forming processes, set for the experiment, are given in Table 1. The powder was loosely poured into the die of $35 \mathrm{~mm}$ diameter heated to the temperature resulting from testing procedure, and then kept there for a sufficient time, for the given amount of powder, until thermal stabilization of a system was reached. Subsequently, the specified pressure was applied by means of a punch, for a specified time period. After removing the load, the samples were pushed out from the die and air-cooled. The selected samples are shown in Fig. 1. The occurrence of cracks was found on the surface of samples formed at the temperature of $400{ }^{\circ} \mathrm{C}$, under the pressure of $50 \mathrm{MPa}$, which can be seen in Fig. 1a and b. In case of materials formed at the temperature of $450{ }^{\circ} \mathrm{C}$ or higher, under the pressure of $100 \mathrm{MPa}$ or $150 \mathrm{MPa}$, the surface of samples was free from visible defects (Fig. 1c).

Table 1. Parameters of hot compaction of Al17Si5Fe3Cu1.1Mg0.6Zr powder

\begin{tabular}{|c|c|c|c|c|c|}
\hline $\begin{array}{c}\text { weight of } \\
\text { powder } \\
\mathrm{g}\end{array}$ & $\begin{array}{l}\text { heating time } \\
\text { min }\end{array}$ & $\begin{array}{l}\text { temperature } \\
{ }^{\circ} \mathrm{C}\end{array}$ & $\begin{array}{c}\text { unit pressure } \\
\mathrm{MPa}\end{array}$ & $\begin{array}{l}\text { pressure } \\
\text { duration } \\
\text { min }\end{array}$ & $\begin{array}{l}\text { cooling } \\
\text { conditions }\end{array}$ \\
\hline \multirow{5}{*}{100} & \multirow{5}{*}{15} & 400 & \multirow{3}{*}{150} & \multirow{5}{*}{5} & \multirow{5}{*}{ air } \\
\hline & & 450 & & & \\
\hline & & 485 & & & \\
\hline & & 500 & $50,100,150$ & & \\
\hline & & 515 & 150 & & \\
\hline
\end{tabular}

a)

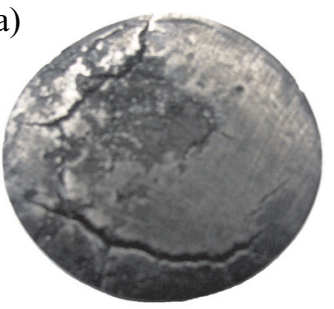

b)

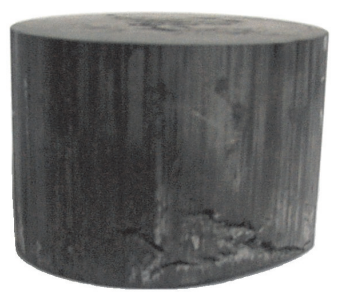

c)

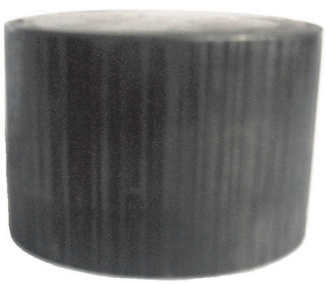

Fig. 1. Shape of samples obtained in closed-die hot compaction of All7Si5Fe3Cu1.1Mg0.6Zr powder: a) temperature $500{ }^{\circ} \mathrm{C}$, punch unit pressure $50 \mathrm{MPa}$; b) $400{ }^{\circ} \mathrm{C}, 150 \mathrm{MPa}$; c) $450{ }^{\circ} \mathrm{C} ; 150 \mathrm{MPa}$ 
The effect of the applied forming parameters on density, selected mechanical properties and microstructure of products was investigated.

\section{RESULTS OF INVESTIGATIONS}

Relative density. Density testing was performed according to Archimedes method, and the obtained results are presented in Figure 2. It was found that compaction of powder, realized with the parameters set for the experiment, results in obtaining products of high relative density. After compaction at the temperature of $450{ }^{\circ} \mathrm{C}$ and higher (Fig. 2a), under the pressure of $100 \mathrm{MPa}$ and $150 \mathrm{MPa}$ (Fig. 2b), the obtained materials showed the density close to that of a solid material.
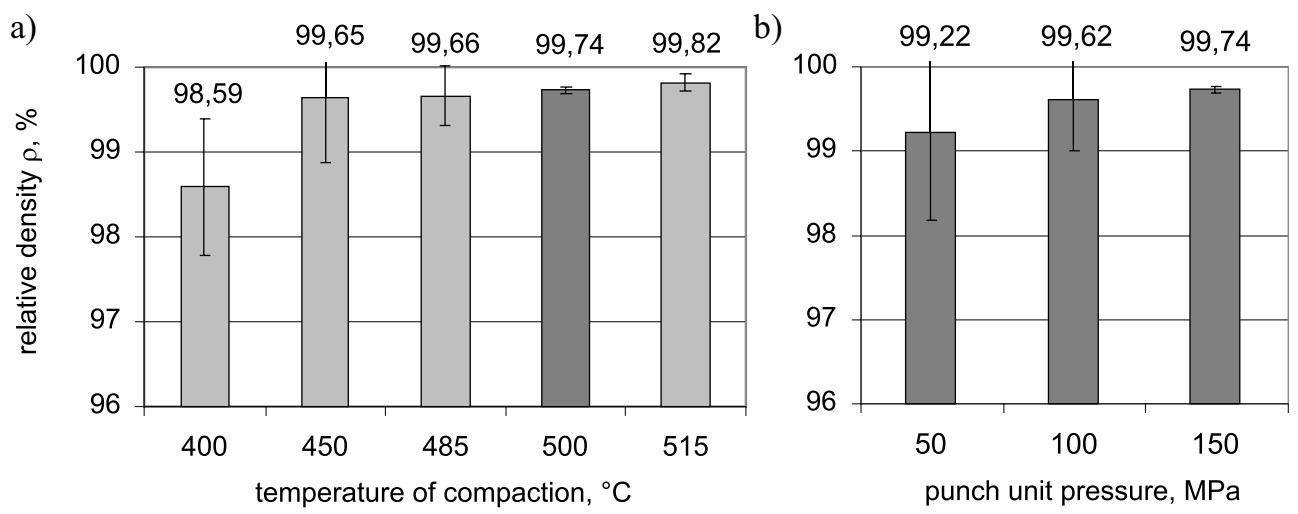

Fig. 2. Influence of parameters of closed-die hot compaction of Al17Si5Fe3Cu1.1Mg0.6Zr powder on relative density: a) effect of temperature, at punch unit pressure $150 \mathrm{MPa}$; b) effect of punch unit pressure, at temperature $500^{\circ} \mathrm{C}$

Hardness. Hardness measurements were performed according to Brinell method, and the results are given in Figure 3, for individual process parameters. HB hardness of investigated materials decreases with increasing temperature of compaction (Fig. 3a). HB values observed for materials obtained in compaction at the temperature of $500{ }^{\circ} \mathrm{C}$, under various unit pressures (Fig. 3b), were found comparable.

Flexural strength. Three-point flexural test was performed at room temperature. The velocity of $0.017 \mathrm{~mm} / \mathrm{s}$ was applied and the length of support span was set to $26 \mathrm{~mm}$. The effect of forming process parameters on flexural strength of products is presented in Figure 4.

The highest average flexural strength, amounting to $733 \mathrm{MPa}$, was found for the material obtained through compaction at the temperature of $485{ }^{\circ} \mathrm{C}$, under punch unit pressure of $150 \mathrm{MPa}$. For samples compacted at temperatures of $400{ }^{\circ} \mathrm{C}$ and $450{ }^{\circ} \mathrm{C}$, under unit pressure of $150 \mathrm{MPa}$, the largest scatter of flexural strength results was observed (Fig. 4a). In case of 
materials compacted at temperatures of $500{ }^{\circ} \mathrm{C}$ and $515^{\circ} \mathrm{C}$, under unit pressure of $150 \mathrm{MPa}$, lower average values of flexural strength were found (Fig. 4a), and the scatter of results was insignificant.

a)

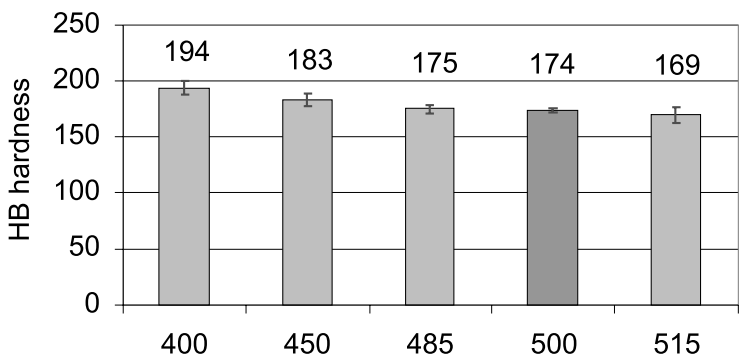

temperature of compaction, ${ }^{\circ} \mathrm{C}$ b)

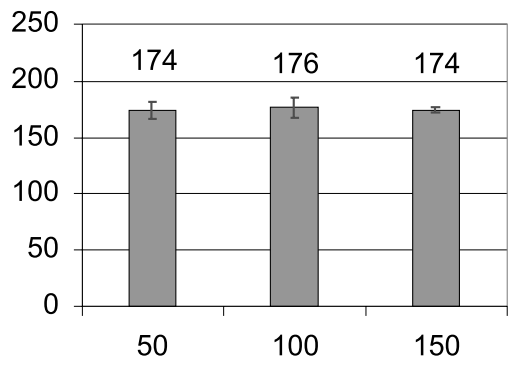

punch unit pressure, $\mathrm{MPa}$

Fig. 3. Influence of parameters of closed-die hot compaction of Al17Si5Fe3Cu1.1Mg0.6Zr powder on HB hardness: a) effect of temperature, at punch unit pressure $150 \mathrm{MPa}$; b) effect of punch unit pressure, at temperature $500^{\circ} \mathrm{C}$

a)

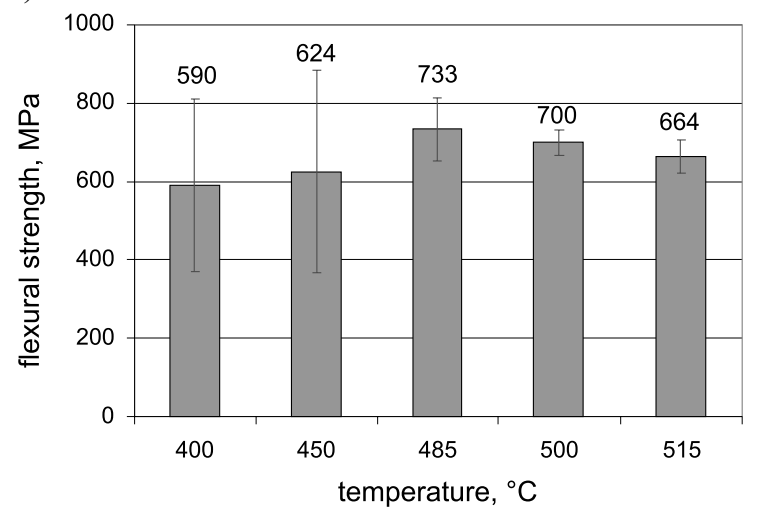

b)

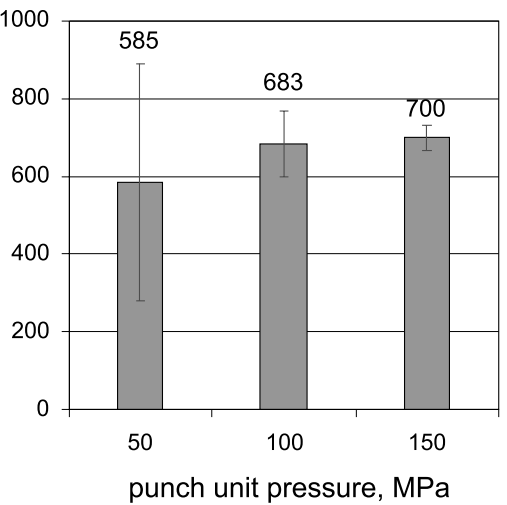

Fig. 4. Influence of parameters of closed-die hot compaction of Al17Si5Fe3Cu1.1Mg0.6Zr powder on flexural strength: a) effect of temperature, at punch unit pressure $150 \mathrm{MPa}$; b) effect of punch unit pressure, at temperature $500{ }^{\circ} \mathrm{C}$

Metallographic examination. Light microscopy was applied to the observation of microstructure. Selected microstructures are presented in Figure 5.

Pores and boundaries of primary powder particles can be seen in the microstructures of materials formed at temperatures not exceeding $450{ }^{\circ} \mathrm{C}$ and under punch unit pressure of $50 \mathrm{MPa}$ (Fig. 5a and b). They gradually fade away with increasing temperature and pressure. As a result of forming at temperatures of $500{ }^{\circ} \mathrm{C}$ or higher, under pressure of $150 \mathrm{MPa}$, the materials obtained showed regular and fine-grained structure, and the surface was free from pores (Fig. 5c and d). 
a)

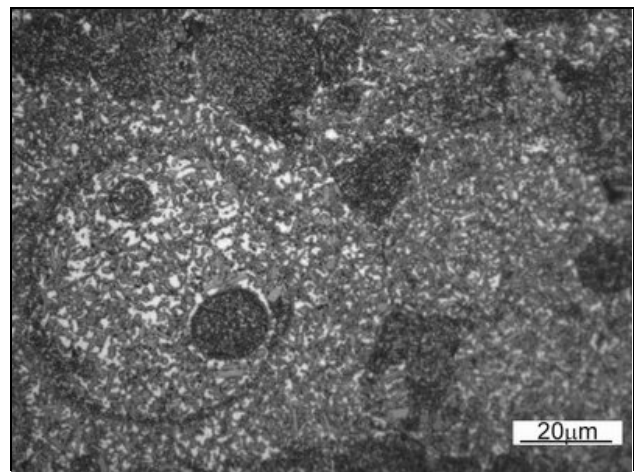

c)

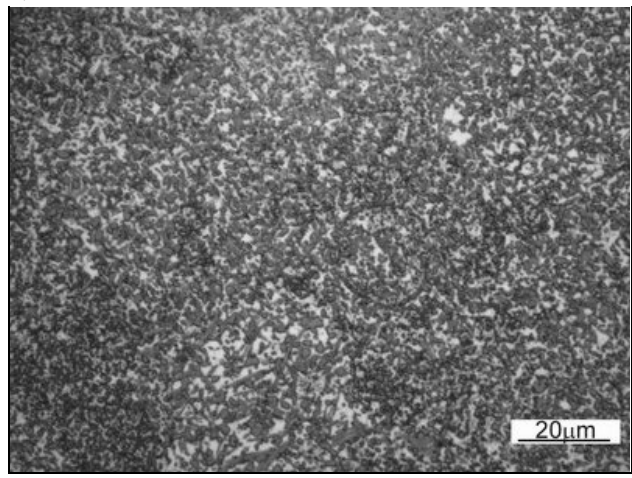

b)

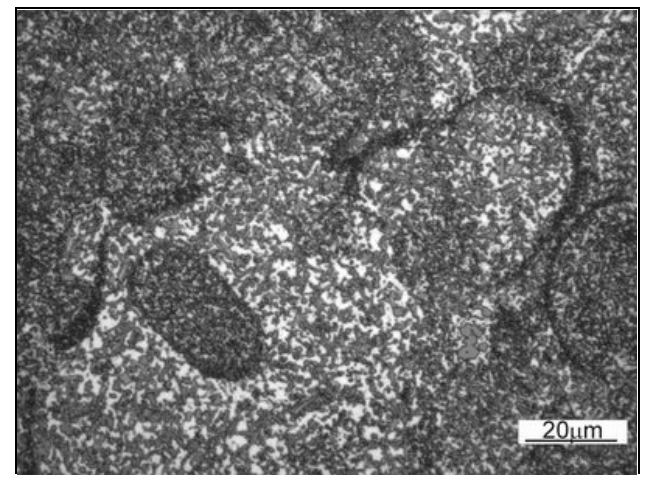

d)

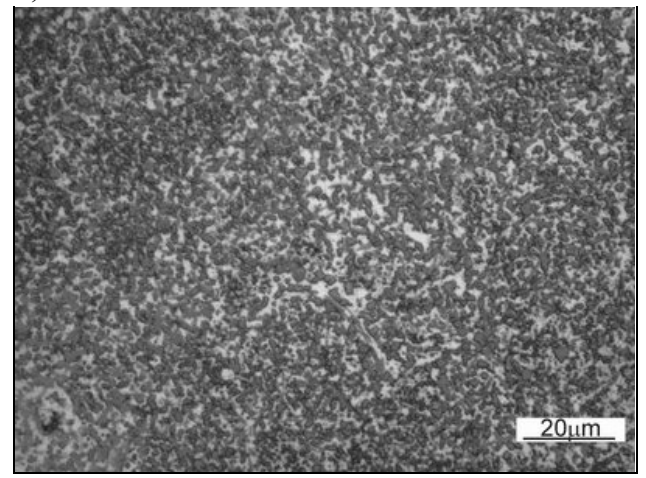

Fig. 5. Microstructures of materials obtained in closed-die hot compaction of Al17Si5Fe3Cu1.1Mg0.6Zr powder. Transverse sections, after etching: a) temperature $400{ }^{\circ} \mathrm{C}$, punch unit pressure $50 \mathrm{MPa}$; b) $450{ }^{\circ} \mathrm{C}, 150 \mathrm{MPa}$; c) $485^{\circ} \mathrm{C}, 150 \mathrm{MPa}$; d) $500{ }^{\circ} \mathrm{C}, 150 \mathrm{MPa}$

\section{CONCLUSIONS}

Basing on the results of investigations of the influence of forming parameters on selected properties of materials produced by isothermal closed-die hot compaction of Al17Si5Fe3Cu1.1Mg0.6Zr alloy powder, it can be concluded as follows:

1. Surface of samples produced at the temperature of $400{ }^{\circ} \mathrm{C}$, under the pressure of $50 \mathrm{MPa}$, reveals the occurrence of cracks. In case of materials formed at higher temperatures, under the pressure of 100 or $150 \mathrm{MPa}$, no such defects were observed.

2. Closed-die hot compaction of powder, realized at the temperature of $450{ }^{\circ} \mathrm{C}$ or higher, under the pressure of $100 \mathrm{MPa}$ and $150 \mathrm{MPa}$, makes it possible to obtain products showing the relative density close to that of a solid material.

3. The decrease of $\mathrm{HB}$ hardness of investigated materials was observed with increasing temperature of compaction. The level of unit pressure, at the temperature of $500{ }^{\circ} \mathrm{C}$, had no effect on hardness. 
4. The highest flexural strength was obtained for the material compacted at the temperature of $485{ }^{\circ} \mathrm{C}$, under punch pressure of $150 \mathrm{MPa}$. For samples compacted under the same pressure at lower temperatures, large scatter of results was found. At the temperatures of $500{ }^{\circ} \mathrm{C}$ and $515^{\circ} \mathrm{C}$ the decrease of flexural strength was observed.

5. The observation of microstructure of materials formed at temperatures not exceeding $450{ }^{\circ} \mathrm{C}$, under punch unit pressure of $50 \mathrm{MPa}$, revealed the occurrence of pores and boundaries of primary powder particles. As a result of powder compaction at the temperature of $485{ }^{\circ} \mathrm{C}$ or higher, under pressure of $150 \mathrm{MPa}$, the materials obtained showed regular and fine-grained structure, and the surface was free from pores.

6. Basing on the results of investigations and observations of microstructure, considering the established conditions of the experiment and scope of research, it can be concluded that the proper process parameters are: the temperature within the range $485-500{ }^{\circ} \mathrm{C}$ and the punch unit pressure of $150 \mathrm{MPa}$.

\section{Acknowledgements}

The research work was financed within a framework of own scientific project (AGH contract no. 10.10.110.864).

\section{REFERENCES}

[1] Rajabi M., Simchi A., Vahidi M., Davami P.: Effect of particle size on the microstructure of rapidly solidified Al-20Si-5Fe-2X (X=Cu, Ni, Cr) powder, Journal of Alloys and Compounds vol. 466, 2008, 111-118

[2] Wojtaszek M., Szczepanik S.: The influence of parameters of hot consolidation and extrusion on chosen properties of PM $\{\mathrm{Al}-\mathrm{Si}-\mathrm{Fe}-\mathrm{Cu}\}$ materials, International conference DF PM 2008: Deformation and Fracture in Structural PM Materials, October 19-22, 2008, Stará Lesná, Slovak Republic: book of abstracts, $57-58$

[3] Wojtaszek M., Szczepanik S.: Aluminium powder based composites reinforced with $\mathrm{Al}_{2} \mathrm{O}_{3}$ fibres: hot forming of aluminium powder - fibres compacts, Metalurgia i Odlewnictwo, vol. 27, 2001, nr 2, 183-196

[4] Wojtaszek M., Durak J., Pernal F.: Badanie i analiza metodą logiki rozmytej parametrów procesu mieszania pod kątem poprawy własności kompozytów otrzymanych z proszków, The research and analysis of mixing process parameters with application of fuzzy logic method for the improvement of properties of PM composites. Kompozyty, 2009, vol. $9 \mathrm{nr}$ 4, 327-331

[5] Hyo S. Lee, Jae S. Yeo, Soon H. Hong, Duk J. Yon, Kyung H. Na: The fabrication process and mechanical properties of $\mathrm{SiC}_{\mathrm{p}} / \mathrm{Al}$-Si metal matrix composites for automobile air-conditioner compressor pistons, Journal of Materials Processing Technology 113, 2001, 202-208

[6] Hath J.E.: Aluminium, Properties and Physical Metallurgy, ASM Metals Park, 1984, 346-347

Received

November 2010 